\title{
RECONHECER A EXPERIÊNCIA E A EXPERTISE DO DOENTE: UM DISPOSITIVO INOVADOR: A UNIVERSIDADE DOS PACIENTES
}

\author{
Catherine Tourette-Turgis* \\ Lennize Pereira-Paulo**
}

\begin{abstract}
RESUMO
O sucesso das estratégias terapêuticas no acompanhamento dos doentes crônicos tem como efeito o aumento da expectativa de vida e uma melhora da qualidade de suas vidas. Novos mecanismos, tal como a educação terapêutica do paciente, questionam o campo conceitual da formação de adultos. Esse artigo propõe considerar a experiência vivenciada da doença como uma oportunidade de aprendizagem e de desenvolvimento para o sujeito doente. O reconhecimento da experiência dos doentes deve abrir para uma validação das competências adquiridas pelos doentes, colocando em questão uma possível profissionalização. A Universidade dos Pacientes, um dispositivo universitário que diploma os doentes, ilustra em que medida o campo das inovações destinadas aos doentes crônicos ainda tem que se desenvolver para que os doentes possam tornar-se atores-chave na melhora da organização dos tratamentos.
\end{abstract}

Palavras-chave: Doenças crônicas. Universidade dos pacientes. Educação e formação ao longo de toda a vida. Educação terapêutica dos pacientes.

\begin{abstract}
RECOGNIZING AND VALIDATING PATIENTS' EXPERIENCE: THE PATIENTS' UNIVERSITY PILOT PROGRAM IN FRANCE

Success of therapeutic strategies in the treatment of chronic patients has the effect of improving their quality of life and helping them to survive while reducing risks of complications. The development of patient education questions the conceptual field and usual training strategies used in adult education. This paper proposes to consider the experience of illness as an opportunity for learning for patients living with a chronic disease person. The recognition of patients' expertise and experience must give them access to news ways of validation and professionalism for those who want to become health actors and participate to the improvement of care organizations. The patients' university is an academic pilot project which is an example of innovation which can be implemented to help people experiencing chronic disease to become keys actors contributing to the improvement of health organizations.
\end{abstract}

Keywords: Chronic disease. Patient education. Expert patient. Long-life learning. Therapeutic education.

* Professora da Université Pierre et Marie Curie UPMC). Diretora de Ensino do Curso de Especialização em Educação Terapêutica da Faculdade de Medicina. Fundadora da Université des Patients, Paris, France. Pesquisadora no Centre National des Arts et Métiers (CRF-CNAM), Paris. E-mail: catherine.tourette-turgis@upmc.fr

** Professora da Université Pierre et Marie Curie (UPMC). Mestre em Saúde e Educação Terapêutica pela Faculdade de Medicina. Pesquisadora no Centre National des Arts et Métiers (CRF-CNAM), Paris. E-mail: lennizepereirapaulo@yahoo.fr 


\section{RESUMEN}

\section{RECONOCER LA EXPERIENCIAL DEL PACIENTE: PROGRAMA PILOTO LLAMADO UNIVERSIDAD DE LOS PACIENTES}

El éxito de las estrategias terapéuticas para trabajar con enfermos crónicos ha tenido el efecto de alargar la vida y mejorar la calidad de vida de estos pacientes. Los nuevos mecanismos, como la educación terapéutica, cuestionan el campo conceptual de la educación de jovenes y adultos. En este artículo se propone tener en cuenta la experiencia vivida con la enfermedad como una oportunidad para el aprendizaje y el desarrollo del sujeto enfermo. El reconocimiento de la experiencia del paciente debe permitir una validación de las competencias adquiridas por los pacientes, cuestionando una posible profesionalización. La Universidad de los pacientes, un dispositivo universitario que diploma los pacientes, muestra en qué medida el campo de innovaciones destinadas a los enfermos crónicos debe aún desarrollarse para que los pacientes pueden llegar a ser protagonistas en la mejora y organización de los tratamientos.

Palabras clave: Enfermedades crónicas. Universidad de los pacientes. Formación continua. Educación terapéutica de los pacientes.

\section{Introdução}

Ao longo dos últimos trintas anos, os avanços terapêuticos têm tido como consequências o aumento da expectativa de vida das pessoas acometidas por doenças crônicas e o desenvolvimento da medicina ambulatória. Doravante, o doente pode receber seus tratamentos em domicílio, inclusive no caso de tratamentos pesados, como quimioterapias ou diálise. Por outro lado, ainda graças aos progressos das terapias, as doenças crônicas se definem hoje como caracterizadas como uma alternância entre fases assintomáticas e fases agudas. Essa evolução portadora de esperança tem consequências não só na organização médica da doença, mas também na experiência cotidiana do doente. De fato, o doente pode, por um lado, continuar exercendo a maior parte dos seus papéis sociais, pessoais e até profissionais nos períodos de calmaria da patologia da qual está sofrendo; mas, por outro lado, deve estar pronto para ser envolvido a qualquer momento por restrições ligadas a cuidados, tratamentos e até voltas para internações hospitalares imprevisíveis. A título de lembrete, $20 \%$ da população francesa e quase $40 \%$ da população brasileira com mais de 18 anos convivem com pelo menos uma doença crônica.

O trabalho médico é dificultado pelas patologias crônicas. Enquanto o objetivo ideal da medicina é curar a doença, no caso de uma doença crônica, o objetivo realista, concreto, é na realidade controlar, na medida do possível, sua evolução, ou pelo menos seus sintomas e suas consequências. É neste sentido que se fala de gestão da doença. Embora esse trabalho de gestão seja comum a todas as doenças crônicas, ele ocorre, a depender das doenças, em situações muito contrastantes sob pelo menos dois pontos de vista. Em primeiro lugar, a gravidade da doença pode ser muito diferente: a sobrevivência de alguém pode ser ameaçada (Insuficiência Renal Crônica grave, Mucoviscidose), ou ainda a autonomia física do doente (Esclerose em Placas, Acidente Vascular Crônico, Poliartrite Reumatoide). Inversamente, certas afecções, por menos perturbadoras que sejam para a pessoa portadora, têm consequências menos definitivas (hipertensão arterial, dor nas costas etc.). Em segundo lugar, os recursos médicos disponíveis para alcançar um resultado médico são dependentes do trabalho que o próprio doente pode conduzir na intimidade da sua vida privada e, logo, também dos recursos de entorno de que ele dispõe.

Algumas doenças crônicas exigem uma modificação comportamental por parte do paciente e um envolvimento maior ou menor da parte dele. 
Espelhando o trabalho requerido pelo paciente, essas doenças crônicas mobilizam, em grau maior ou menor entre os cuidadores, o exercício e a implementação de algum tipo de suporte. A maioria das doenças mobiliza uma mudança pessoal, quando o tratamento da patologia inclui ao mesmo tempo um tratamento medicamentoso e um "tratamento comportamental". Diferentemente de outras doenças orgânicas, as doenças cardiovasculares, a infecção pelo HIV, o diabetes, a obesidade, o câncer de pulmão, para citar apenas algumas, não são vistas como uma experiência difícil, mas como a sanção de um estilo de vida, até mesmo como um fracasso de autogoverno (TOURETTE-TURGIS; THIEVENAZ, 2013). Sua prevenção torna-se o símbolo de uma guerra que cada indivíduo deveria travar contra ele mesmo, usando estratégias de cálculos cujos algoritmos, ferramentas e procedimentos lhe são fornecidos por todos os cuidadores que intervêm neste campo.

Os públicos doentes são cada vez mais os destinatários de uma oferta de formação ou educação na medida em que as expectativas sanitárias colocam cada vez mais nos próprios doentes a escolha de engajar-se em mudanças comportamentais, implicando uma modificação dos seus hábitos alimentares (no caso da diabetes, obesidade) ou até dos seus hábitos sexuais (no caso de doenças sexualmente transmissíveis - DST). Grande parte do trabalho terapêutico na maioria das doenças crônicas consiste, para o sujeito portador da doença, em conseguir introduzir na sua vida novas atividades, mas também em atividades de intervenção sobre si próprio, como as atividades terapêuticas. Essas atividades terapêuticas exigem uma transformação de si mesmo, ou até uma educação de si mesmo difícil de conduzir, pois envolvem o indivíduo em vários registros e mobilizam recursos combinados, concorrentes e conflitantes. Perder peso, por exemplo, exige autodisciplina, a gestão dos prazeres e dos fracassos, assim como das sensações e dos sinais como a fome e a saciedade, que são pontos de referências que não se pode transformar sem violentar o organismo fisiológico. A prevenção da transmissão das DST implica a organização erótica pessoal, e tentar modificar esta organização pode trazer algum risco para o indivíduo.

\section{Doença, educação e formação dos adultos}

A doença é pouco presente nos projetos de educação e de formação dos adultos. Talvez seja paradoxal pedir aos profissionais de educação e de formação para construir programas de formação com finalidade de melhorar, através de aprendizagens cognitivas, emocionais e existenciais, a qualidade de vida de pessoas que têm que lidar com experiências sofridas tais como esta, representada por uma doença crônica, com duração incerta e prognóstico severo. Podemos nos interrogar sobre os paradoxos trazidos por uma ambição educativa para com pessoas confrontadas com a necessidade de aprender modos de fazer, de dizer e de agir, possibilitando-lhes melhor convivência com a doença em um espaço-tempo modificado para todo o sempre. Neste sentido, temos de constatar a ausência de uma tradição de pesquisa em formação dos adultos doentes. De fato, os modelos de intervenção psicossociológica tradicionalmente aplicados neste campo também foram elaborados para pessoas saudáveis, envolvidas em projetos de desenvolvimento pessoal e profissional baseados nas noções de "projeto" e de "futuro". Esses quadros referenciais se baseiam no contrato social implícito predefinido no âmbito do qual o sujeito aprendente é concebido como estando capaz de agir, antecipar e seguir projetando-se em um continuum biológico. No entanto, nossa experiência de formação de grupos de doentes tem nos mostrado a necessidade de um questionamento radical dos conteúdos e das modalidades pedagógicas de transmissão dos saberes envolvidos. Com efeito, ministrar ensino médico a respeito de uma doença para um público que sofre desta mesma doença exige um trabalho prévio de transposição didática do saber médico. A incerteza, a finitude, o prognóstico vital envolvido, o risco, a morte anunciada, o fracasso dos tratamentos são temas recorrentes nas disciplinas de medicina, porém, como trabalhar estes temas no contexto de um ensino médico dado para doentes diretamente tocados pela doença tal qual está se falando? Se existir uma tradição ética centrada nas pedagogias da esperança, do projeto e da felicidade na educação dos adultos saudáveis, a formação de adultos doentes requer a coconstrução 
com os doentes de um campo de pesquisas sobre as pedagogias mais apropriadas na área do ensino médico a ser desenvolvido para públicos diretamente envolvidos. A formação de adultos doentes em grupo, diferente da consulta médica ou do diálogo íntimo entre o médico e o doente, é um dispositivo que não pode cumprir suas funções de contenção e de sustentação se não houver um trabalho prévio de reflexão sobre os conteúdos dos saberes, sobre a postura ética necessária e sobre o respeito dos direitos dos doentes, trabalho conduzido individualmente com os doentes e coletivamente com as associações de doentes.

\section{As tendências teóricas atuais na Educação Terapêutica do Paciente (ETP)}

A expressão “educação terapêutica ${ }^{1}$ foi definida na Europa pela primeira vez por J. Ph. Assal, responsável por um grupo de trabalho na OMS que propõe, desde 1998, esta definição:

A educação terapêutica do paciente deve permitir aos pacientes adquirirem e conservarem as competências, ajudando-lhes a viver de maneira otimzada com sua doença. Trata-se de um processo permanente, integrado nos cuidados e centrado no doente. A educação implica em atividades organizadas de sensibilização, informação e aprendizagem da autogestão e do suporte psicológico, relativas à doença e ao tratamento prescrito, aos cuidados, ao contexto hospitalar e de tratamento, às informações organizacionais, e aos comportamentos de saúde e de doença. A educação terapêutica objetiva ajudar os pacientes e suas famílias a entenderem melhor a doença e o tratamento, a cooperarem com os cuidadores, a viverem de maneira mais saudável e a manterem ou melhorarem sua qualidade de vida. (ORGANIZAÇÃO MUNDIAL DA SAÚDE, 1998, p. 13).

Quer sejam designadas como "educação do paciente" ou "educação terapêutica", estratégias educativas dirigidas para os doentes e seus familiares desenvolveram-se amplamente a partir dos anos 1990. Compartilham as mesmas origens: por um lado, as correntes da prevenção da saúde expostas antes, e, por outro lado, o poder crescente das associações de doentes. Na prática, a maneira como

1 Segundo Lacroix e Assal (1998), seria mais adequado falar de "formação terapêutica dos pacientes". os doentes vivem seus tratamentos, ou sua doença, foi identificada como uma maneira de gerir melhor o acompanhamento terapêutico. Por conta disso, na maior parte dos países, programas de educação para os diversos tratamentos foram desenvolvidos. Estas abordagens podem ser diretamente ligadas a uma patologia e às suas associações de doentes, ao passo que outras se assumem como visando o bem-estar ou a saúde em geral. De maneira mais geral, observa-se uma evolução que, partindo da vontade de educar os pacientes quanto às suas terapias, se abre hoje para uma vontade global de educação com finalidade terapêutica. Neste ponto, também os limites são vagos e os objetivos diferem segundo os países (VAN BALLEKOM, 2008). O fato é que este tipo de estratégia, qualquer que seja sua forma, se impôs nos textos de leis e nas práticas cuidadoras na maior parte dos países desenvolvidos.

A importância das doenças crônicas e dos seus efeitos, tanto em nível individual quanto social, é uma caraterística da maioria dos países industrializados neste início de século XXI. Este fenômeno instala-se a partir de meados do século anterior, graças aos progressos na área médica e às melhoras das condições socioeconômicas das populações destes países. Uma literatura importante tem mostrado como essa presença cada vez mais numerosa de pessoas convivendo com uma doença crônica modifica por sua vez as caraterísticas socioeconômicas e como a sociedade se transforma para acolher esses novos doentes. Como Jouet, Flora e Las Vergnas (2010, p. 36) resumem: “A educação terapêutica do paciente (ETP) na França está historicamente ligada ao diabete e hoje se exerce na base de sucessos confirmados." A educação terapêutica foi depois transposta e adaptada a várias outras doenças crônicas, tais como a asma brônquica, a broncopneumopatia crônica obstrutiva, as doenças cardiovasculares. Ela está historicamente ligada às noções de aconselhamento e de empoderamento (FREIRE, 1971) desenvolvidas no contexto dos tratamentos ligados à infecção pelo HIV-AIDS (TOURETTE-TURGIS, 1996).

Reencontramos na descrição dos primeiros programas de educação a influência de uma corrente pedagógica em ciências da educação, "a pedagogia por objetivos" (HAMELINE,1983), e depois vimos surgir a corrente das teorias socioconstrutivistas 
na aprendizagem (VYGOTSKI, 1985), correntes essas que colocam como hipótese central que um conhecimento toma "naturalmente sentido" quando aprendido em ação e confrontado com saberes anteriores. Conhecer é um processo ativo: o conhecimento se vive e se conquista agindo. Trata-se, então, na educação terapêutica, de construir situações de aprendizagem a partir do que vivem os pacientes e dos conhecimentos que possuem deles.

A maioria das pesquisas realizadas sobre a educação terapêutica desde o final dos anos 1990 é composta de trabalhos relativos às expectativas médicas da educação, no sentido em que se trata de demonstrar se a variável "educação" é ou não é uma variável de ajuste. Esses trabalhos se subdividem em duas grandes categorias: os que são relativos à avaliação dos resultados da educação terapêutica sobre a saúde dos pacientes; e os que tratam dos dispositivos de intervenção usados nestes programas. A introdução explícita de uma atividade educativa na atividade cuidadora levanta questionamentos epistemológicos. De um lado, trata-se de compreender a maneira como é atribuída a legitimidade de conceber e implementar uma ação de educação dirigida para um público exposto a uma "vulnerabilidade biológica". Quais são, por exemplo, as particularidades a considerar em um sujeito-aprendente-doente exposto a um saber sobre sua doença? Formulamos a hipótese de uma forte singularidade das situações em razão das caraterísticas peculiares do adulto doente crônico que legitima a necessidade de desenvolver um campo de prática e pesquisa autônomo sobre essas questões. O desenvolvimento da ação educativa modifica certas representações da atividade cuidadora, notadamente as representações relativas às aprendizagens de autocuidado (aprendizagem de autoinjeção, gestos de autoexame, ensinar para os pacientes como identificar sintomas, antecipar crises, acessos). Por outro lado, a formação dos cuidadores para a ETP traz questões quanto às modalidades de transposição dos saberes científicos disponíveis na medicina em saberes suscetíveis de serem apropriados pelos pacientes. Os conteúdos destes ensinamentos não são transponíveis tais quais para um público de pacientes cuja experiência subjetiva da doença pode representar um obstáculo cognitivo e psíquico para o acesso a esses ensina- mentos. A formação de cuidadores-educadores é, por exemplo, na França, obrigatória para ministrar a educação terapêutica. Esta se realiza em um formato de 42 horas e se baseia em um referencial nacional de competências requisitadas pertencendo a quatro áreas: médica, pedagógica, organizacional e metodológica. As equipes que desejam implantar programas de educação terapêutica nos serviços terapêuticos e nas redes de saúde devem previamente obter uma autorização e um convênio concedidos pela agência regional de saúde da qual dependem.

\section{Tendências emergentes em educação do paciente: a doença como episódio autodidático}

Retomando a definição da autodidaxia como um conjunto "dos modos de aquisição de saberes, de know-how - saber-fazer - e de atitudes específicas na relação com essas aprendizagens (organizadas), fora dos contextos escolares ou de formação qualquer que seja sua natureza" (BÉZILLE, 2003, p. 109), podemos considerar a experiência da doença como fazendo parte de uma autoaprendizagem do tipo "experiencial"

Os "saber-passar" que um sujeito mobiliza (LESOURD, 2008) durante as crises e rupturas da existência aparece como um quadro conceitual para ser mobilizado em caso de doença. Este é um campo disciplinar ainda pouco teorizado nos programas clássicos de educação terapêutica. As ferramentas conceituais desenvolvidas pelos trabalhos atuais sobre a autodidaxia (BÉZILLE, 2003), sobre a "teoria dos momentos de ruptura existencial", parecem adequadas para promover pesquisas neste sentido.

As histórias de vida já penetraram no campo da formação e da saúde (NIEWIADOMSKI, 2009), mas como observam Jouet, Flora e Las Vergnas (2010, p. 61, grifo do autor):

Retrospectivamente, é surpreendente que o campo da doença e dos saberes dos doentes não tenha sido mais cedo um dos cavalos de batalha dos proponentes das 'formações experienciais'. E, de fato, tendo visto as revistas de literatura, fica confirmado que mesmo quando a questão dos 'saberes da pobreza' foi identificada e estudada, os saberes experienciais dos doentes demoram de serem considerados. 
Segundo Niewiadomski (2009, p. 44),

[...] a pertinência dos modelos que vão ser mobilizados implica considerar, [...] quando se trata de pessoas doentes, [...] a formação, não a partir dos registros expositivos e de transmissão tradicionalmente usados em pedagogia, mas sim a partir de modelos mais integrativos, possibilitando considerar e valorizar as conquistas experienciais dos aprendentes em prol de um processo de formação, envolvendo profundamente a própria existência do sujeito.

Esse mesmo autor abriu caminhos terapêuticos para o tratamento das dependências químicas. Ele propõe um caminho complementar ao modelo teórico biomédico usado em alcoologia, o uso da metodologia das "histórias de vida" proposta para pequenos grupos de pacientes no âmbito das suas estadas em instituição especializada sobre a forma de atividades de escrita, e de trabalho coletivo sobre os relatos. Sua abordagem remete ao conceito de biografização de Christine Delory-Momberger (2003, p. 6) definido como "a maneira pela qual os indivíduos biografizam suas experiências, e em primeiro lugar, a maneira pela qual eles integram nas suas construções biográficas o que eles fazem e o que eles são". Os trabalhos conduzidos por Delory-Momberger sobre o trabalho biográfico representam uma oportunidade imperdível no mundo da saúde e da educação, no sentido em que a doença é uma experiência que mobiliza de fato uma intensa atividade biográfica espontânea, mas também no sentido em que os cuidadores que praticam a educação colocam com frequência os doentes em situação de ter que contar sua história, correndo o risco de que a narrativa seja usada como uma forma de controle do respeito, pelo paciente, das normas de tratamento e de saúde que dele se espera.

Observa-se também surgir na área médica uma nova tendência: "a medicina narrativa", que, segundo uma das suas idealizadoras (CHARON, 2006), se enraíza na filosofia existencial e tem como ferramenta a prática narrativa. ${ }^{2}$ A troca das narrativas escritas é seu suporte. É essencial acolher a história do paciente, ouvir como ele interpreta sua doença e complementar essa história com as dos

\footnotetext{
2 A medicina narrativa é ensinada na Columbia University, na McGill University, em Montreal, e na faculdade de medicina René Descartes, em Paris.
}

médicos, das enfermeiras, da família. Os autores das correntes emergentes colocam à nossa disposição outros conceitos para pensar "a educação terapêutica". Porém, a primeira etapa consiste em deixar o paciente ocupar o lugar que lhe pertence nos dispositivos de formação. Como Dominicé e Jacquemet (2009, p. 29) escrevem:

O paciente é, como o aprendente, um sujeito em formação, no sentido em que a noção de relação com a doença ou com a saúde abre perspectivas análogas a estas que foram iniciadas pela colocação em evidência do lugar da relação ao saber nas relações com a formação.

\section{A atividade de manutenção em vida de si mesmo: um verdadeiro trabalho, uma fonte de desenvolvimento}

Tem sido privilegiado nos escritos psicológicos o desenvolvimento da doença na história do sujeito, ao passo que nosso trabalho de acompanhamento tem sido privilegiar o desenvolvimento do sujeito na doença. Foi por privilegiar esse ponto de vista que nosso olhar foi desviado de uma concepção da doença como entrave ao desenvolvimento de um sujeito e elaboramos uma visão da doença como etapa de desenvolvimento. Ao convidar os doentes a falar de sua "profissão" de doente, ou seja, ao inventar uma hipótese teórica, pudemos constatar com grande nitidez, ainda mais numa época de carência da doença e da resposta médica, que os pacientes conseguiam transformar a experiência da sua doença em meio de viver outras experiências sociais e coletivas, que apresentavam um interesse para a comunidade e a sociedade, revelando também problemáticas epistêmicas inéditas. A doença não é uma ruptura de vida, ela é outra vida. Como qualquer humano que está vivendo sua vida, o doente conduz, exerce um certo número de atividades além de suas outras atividades. Parte do seu tempo é dedicado ao exercício de atividades muitas vezes novas para ele e essas consistem em agir, pensar para agir e agir para pensar. O conjunto tem um efeito de transformação de si mesmo. A evidenciação deste registro questiona a maioria das atitudes que fundamentam o acompanhamento, tais como a assimetria das posições, a ausência de igualdade das situações e, sobretudo no caso da doença, o fato de 
que na maior parte do tempo o acompanhamento é evocado para reforçar a privação do poder de agir do doente, já que essa privação faz exatamente parte da definição social da doença. Se pensarmos no doente como "um trabalhador do invisível", acompanhar implica que nos interessemos pelas atividades que ele conduz, pelas condições nas quais ele as conduz, enfim, que despatologizemos a visão que temos do doente. Os doentes crônicos sabem que não vão se curar, eles lutam para sobreviver nas melhores condições. Eles convivem com uma primeira doença crônica que tentam controlar ou adiar, e muitas vezes são confrontados com uma segunda ou até uma terceira doença crônica. Muitas vezes se colocou a doença como tendo um efeito identitário, mas o que acontece quando um sujeito sofre de várias patologias, exigindo de seus órgãos e de seu funcionamento fisiológico de várias formas?

\section{Definir "A atividade" do doente" (no singular)}

Escolhemos falar da "atividade" do doente para designar o conjunto das transações situadas que o sujeito estabelece com seu entorno ao longo de toda a sua existência (preocupação consigo mesmo, com os outros e com a manutenção do mundo) e as transformações que ele opera nessa oportunidade sobre seu entorno e sobre si mesmo (TOURETTE-TURGIS; THIEVENAZ, 2013).

Escolhemos falar da "atividade produtiva" do doente, enfatizando que essa atividade é produtora de uma mais-valia, de um conjunto de bens ou de serviços (atividades pertencendo ao domínio do atendimento das necessidades do corpo humano, da manutenção do elo social) sem que necessariamente estes sejam reconhecidos social ou economicamente.

Acontece que esse trabalho invisível, silencioso ou tornado invisível (apagamento dos rastros) constitui um dos fundamentos da manutenção do elo social (por exemplo, não morrer é dar esperança aos outros doentes - interesses individuais e coletivos consubstancialmente ligados).

Podemos distinguir "a atividade do doente", compreendida como esforço para manter-se no continuum dos seres vivos, das diferentes "ativi- dades" que compõem e participam deste processo. Conviver com uma doença, durante vinte ou trinta anos, é o equivalente a uma vida produtiva, da qual uma parte deve ser dedicada ao desdobramento de um conjunto de atividades servindo à manutenção em vida de si mesmo.

A pergunta feita é a seguinte: em que medida será possível identificar, tornar inteligível e acompanhar a atividade implementada por um sujeito doente crônico para assegurar a manutenção de si em vida? Na hierarquização e na competição entre atividades humanas, não encontramos definição relativa às modalidades de exercício desta atividade singular, que consiste para um ser humano vivo em exercer, a partir da manuseio de um conjunto de ferramentas e de objetos específicos (medicamentos), um conjunto de atividades caraterizadas por múltiplos usos de si mesmo que até hoje nunca foi socialmente valorizado, como se faz com qualquer outra atividade produtiva ou da manutenção das suas forças de reprodução. A doença exige a aquisição de um poder de ação sobre si mesmo, sobre outrem e sobre o mundo: ela mobiliza um novo campo de atividades no universo das atividades dos outros, e, inversamente, ela implica iniciar atividades de outros no seu mundo, o que definimos como "a delegação da preocupação de si mesmo para um outro". As atividades realizadas pelo doente ultrapassam muitas vezes o que os doentes tinham pensado como suas possibilidades e suas capacidades esperadas. A doença é uma atividade não só fisiológica e biológica, mas também uma atividade tal como a vida, ou seja, uma atividade na qual se experimenta uma subjetividade.

\section{Definir "As atividades" do doente (no plural)}

Escolhemos falar das "atividades" do doente a fim de designar o conjunto dos processos implementados pelo sujeito para servir à manutenção em vida de si mesmo. Essas atividades possuem uma unidade que lhes é própria e são caraterizadas em função do tipo de materiais que mobilizam, dos esforços que requerem e dos seus produtos (esperados e inesperados).

Essas diversas atividades mantêm entre si ligações de interdependência e de reciprocidade 
e concorrem assim para o que chamamos de atividade global do doente. Essas diversas atividades se agrupam em vários contemplados: si mesmo, o outro ou a uma comunidade de atores entre si; e elas não são necessariamente reconhecidas nem explicitamente avaliadas ("trabalho rentável” para si ou para a coletividade).

\section{Atribuir uma validade aos conhecimentos produzidos a partir da experiência vivida}

Quanto ao status da pessoa que produz conhecimentos sobre a experiência vivida da doença, os doentes são, no momento atual, pouco convidados nos espaços de produção de conhecimentos relativos às suas experiências, seus saberes, seus modos de fazer. Quando são convidados, é no âmbito de um tipo de dispositivo que lhes propõe virem "dar o testemunho" de suas experiências e que os coloca em posição de "testemunha álibi" do discurso dos outros. Eles vêm para demostrar que o que é dito a seu respeito está certo, mas não são eles que constroem a pauta do encontro científico, acadêmico ou político. Isso tem um profundo impacto sobre o reconhecimento da legitimidade da produção de conhecimentos, no sentido em que a validade destes está intimamente ligada ao status institucional do seu lugar de produção. A supremacia dada à organização acadêmica dos conhecimentos nos priva dos saberes construídos por uma parte da população, assim como da experiência vivenciada de categorias de populações cuja palavra não é levada em consideração e que, no entanto, participam da manutenção do mundo ao manterem-se vivendo em condições precárias. Por este motivo, a Universidade dos Pacientes é um dispositivo que apresentamos aqui como a ilustração, na ação e pela ação, de um conceito central que viemos desenvolvendo há vários anos e que concebe os doentes como sujeitos produtores de saberes, mas também como sujeitos participando da produção e da manutenção da vida. As competências adquiridas por eles em situações como essas, geradas pela doença crônica de longa duração, são competências que, uma vez transpostas em outros contextos sociais, representam uma grande utilidade social.

\section{Identificar os processos efetivos de reelaboração da experiência dos sujeitos portadores de uma doença: uma tarefa prévia à elaboração dos dispositivos de formação e acompanhamento}

As noções de competências do paciente, de aprendizagem, de saberes usados na "educação-formação dos doentes" são construtos sociais que designam realidades fugindo da análise e usam uma semântica da intervenção desenvolvida por experts tentando transpor para a formação dos doentes os modelos para a ação centrados sobre o alcance de um grau de desempenho. Nessa ótica, cabe aos formadores apreenderem o sujeito em formação enquanto pessoa que vive, se constrói e se projeta em dado ambiente. Um programa de formação para adultos costuma basear-se em um referencial de atividades profissionais referentes a finalidades profissionais ou sociais esperadas.

Mas, no caso da formação dos doentes, as finalidades sociais são orientadas para a melhora da sua qualidade de vida através do exercício das suas capacidades de desempenhar um certo número de atividades que contribuam para tanto. $\mathrm{O}$ surgimento de referenciais de competências, em um campo excluído do trabalho e da profissionalização, constitui um problema em si, pois ao dar ao doente a possibilidade, pelo viés da formação, de saber entender e analisar o que ele está fazendo, ele analisa suas condutas de ação e, no mesmo ato, produz conhecimentos sobre as tarefas que realiza, mostrando o descompasso existente entre as tarefas prescritas e o real da sua atividade. Quer seja nomeada "educação terapêutica" ou "formação de paciente", a identificação das múltiplas dimensões da experiência do doente ${ }^{3}$ é indissociável da identificação das situações concretas em que ele desempenha essas atividades. Logo, os dispositivos de educação ou de formação de doentes devem integrar as dimensões não programáveis das atividades a serem realizadas pelo doente, a incerteza embutida na própria situação de doença, a interatividade no sentido em que o doente transforme a situação tanto quanto ele é transformado por ela e é o ator que em primeira instância pode aprender com a situação.

3 Preferimos a expressão "mecanismo de formação". 
Quanto aos dispositivos de acompanhamento dirigidos aos públicos portadores de uma ou várias doenças crônicas, é necessário que a formação seja concebida e implementada levando em consideração as singularidades contextuais próprias de cada participante, singularidades cuja identificação é tarefa importante dos formadores.

Formar os doentes implica, portanto, uma sensibilização dos formadores para a análise das tarefas que estes devem desempenhar previamente à concepção das formações a serem construídas e implementadas. Não se trata de ensinar para as pessoas vulnerabilizadas estratégias de adaptação almejando sua adesão às normas médicas, sociais e comportamentais esperadas, como se ensina ao "bom doente" a permanecer um bom doente, e isso mesmo no final da sua vida. São obviamente as teorias normativas que costumam enfatizar "o trabalho de luto", ao passo que preferimos substitui-lo por "o trabalho do sentido". Nos dispositivos terapêuticos para sujeitos portadores de doenças crônicas com prognóstico incerto, cabe aos trabalhadores sociais poder apreender todo sujeito humano enquanto pessoa que vive, se constrói e se projeta em dado ambiente. O dispositivo de acompanhamento deve então ser apreendido e organizado levando em consideração as singularidades contextuais próprias a cada sujeito.

\section{Um exemplo de reconhecimento da experiência dos doentes: a Universidade dos Pacientes}

As atividades dos doentes a serviço da coletividade fazem parte de um novo paradigma social, pedindo seu reconhecimento e sua valorização, pois em nossas sociedades as expectativas dos voluntários têm evoluído sensivelmente, em especial o desejo de beneficiar em resposta ao seu investimento, uma valorização de seu percurso. No caso de pessoas doentes, e vimos isso claramente no caso da AIDS, muitas pessoas que tinham desempenhado funções e atividades voluntárias retomaram o caminho de volta ao trabalho concomitantemente com a volta da saúde trazida pela chegada dos coquetéis em 1996. Entre essas pessoas, o fato de terem desempenhado funções de acompanhamento, de escuta, de formação, de pesquisa, despertou sua vontade de se profissionalizarem em espaços organizacionais em ruptura com suas profissões anteriores. Evidenciou-se rapidamente que as competências adquiridas pelos voluntários de associação de luta contra a AIDS eram transferíveis, tais como: a tomada de responsabilidade, o espírito de iniciativa, as capacidades de comunicação e de organização, a gestão de projetos inovadores, a gestão de equipes.

E foi esssa constatação que nos levou a criar a primeira universidade de pacientes na França, em 2009, na Universidade Pierre et Marie Curie (Faculdade de Medicina), em Paris. Com efeito, tínhamos visto em 1997 que a Universidade da Califórnia abria cursos com diploma e gratuitos para os doentes que tinham sobrevivido à AIDS e desejavam reinserir-se profissionalmente e usar sua experiência no serviço à comunidade. Também participamos, nos Estados Unidos, da criação das universidades AIDS destinadas aos voluntários que desejavam o reconhecimento da experiência adquirida nas associações e obter um diploma permitindo-lhes continuar seu desenvolvimento profissional para poder agir em outros níveis nos equipamentos de saúde. Na França, através do direito à educação e à formação ao longo de toda a vida (1998) e dos dispositivos de validação dos conhecimentos adquiridos na experiência profissional e pessoal (1985 e 2002), as universidade têm total liberdade e são muito solicitadas por seus dirigentes para incluir os públicos em situação de vulnerabilidade ou de precariedade e propor percursos e currículos com obtenção de diploma. Ao lançar mão da expressão "universidade dos pacientes", alimentamos várias intenções. A primeira é de interpelar a universidade quanto aos seus deveres enquanto empresa pública para com as populações vulneráveis, pois o dever de uma universidade é antecipar e atender as necessidades de todos os públicos que precisam de um diploma ou de um curso com diploma para encontrar seu lugar na sociedade. A segunda é que a passagem dos doentes pela universidade confere-lhes um status de estudante que os descansa do seu status de doente, muitas vezes desqualificante ao olhar dos outros, e lhes permite um recomeçar. Aprender, descobrir o prazer de estudar, contribui para sua volta à saúde. A terceira intenção é propor a todas as faculdades de medicina a implantação 
das universidade de pacientes de forma a tornar visível a intenção de colocar o paciente no centro da formação dos médicos, ao formar doentes no mesmo lugar para sua participação nos ensinamentos ministrados nas faculdades de medicina.

Começamos incluindo nos diplomas sem educação terapêutica os doentes e os voluntários de associações que de fato já assumiam funções de ensino, de formação de seus pares ou de cuidadores. Depois, estudamos as necessidades formuladas pelos doentes, pelas associações, assim como as recomendações e as necessidades das agências regionais de saúde. E estamos construindo os certificados universitários para atender essas necessidades, em especial um certificado para a formação de doentes, desejando tornar-se representante dos usuários, e outro certificado para um percurso universitário de formação dos doentes desejando formar-se na gestão de casos de câncer. Até hoje a universidade dos pacientes diplomou ou deu certificados universitários em educação terapêutica para mais de 103 pacientes, dos quais 25 por educação à distância na África francófona, com o suporte do Ministério das Relações Exteriores e de vários patrocínios. Desses pacientes, 30\% encontraram um emprego na área da formação de adultos, na educação terapêutica nas associações de pacientes, no setor privado. Cinco pacientes criaram pequenas empresas próprias de oferta de serviço de secretariado, animação de comunidades on-line, relações públicas com formação em educação terapêutica. Três pacientes diplomados estão atualmente matriculados no doutorado. Após a obtenção de um Diploma Universitário, 10\% dos pacientes prosseguiram para a licença e o mestrado. Cinco pacientes usaram seu diploma para criar ou fortalecer associações (Renaloo, Mon réseau cancer du sein e Association Francophone pour Vaincre les Douleurs), cinco pacientes escreveram juntos um manual de autoformação intitulado $D o$ you speak docteur? Comment communiquer efficacement avec le médecin sur la douleur chronique (Você fala médico? Como comunicar-se de forma eficiente com o médico sobre a dor crônica), que foi premiado duas vezes no festival de comunicação sobre saúde em Deauville, em 2014. Um paciente criou um software "PainWatcher" (Vigilante da Dor), atualmente em desenvolvimento.
Um paciente, ao final da sua tese, tornou-se professor e responsável de um programa no âmbito do "paciente parceiro" na Universidade de Montreal. Um paciente diplomado na Universidade dos Pacientes da UPMC estimulou a criação da Universidade dos Pacientes de Grenoble. A cada ano, os pacientes diplomados pela Universidade dos Pacientes ministram mais de 60 horas-aula nos currículos da UPMC, nos Institutos de Formação em Cuidados de Enfermagem, nas associações, e mais de 50 horas-aula em organismos de formação. Eles desempenham a coanimação de oficinas em educação terapêutica em vários hospitais, em especial os centros da Assistência Pública-Hospitais de Paris, assim como em várias outras regiões graças à nossa contratação no âmbito nacional. Participaram, enquanto copesquisadores, do Seminário da EHEC, a Escola de Altos Estudos em Ciências Sociais, e expuseram sua contribuição, enquanto doentes, para a pesquisa em 2013 e 2014. Uma primeira avaliação empírica realizada em 20132014 mostra que a passagem pela universidade e a coformação com cuidadores tem um impacto muito profundo sobre a autoestima, a saúde percebida e o sentimento identitário. A passagem pelo status de estudante estimula uma retomada de controle sobre sua própria vida e sua saúde. Estudar pacientes e cuidadores em um mesmo currículo representa uma experiência pedagógica inovadora e é útil tanto para os cuidadores como para os pacientes, que descobrem a psicologia e a vulnerabilidade dos cuidadores.

"A Universidade dos Pacientes", ao considerar os doentes como produtores de saberes, mas também como sujeitos exercendo certo número de atividades a serviço de sua "manutenção de si em vida", mostra por que a valorização destas atividades requer a criação de dispositivos objetivando o reconhecimento tanto dos sujeitos que as desempenham quanto das ações realizadas. A Universidade dos Pacientes busca ao mesmo tempo levar em consideração os saberes da experiência da doença e atender as necessidades dos doentes em termos de formação com diploma no campo da educação e da formação de adultos. O funcionamento comum da instituição universitária e dos dispositivos de educação continuada não é adaptado aos indivíduos confrontados com os imprevistos da cronicidade de 
seus estados biológicos. Enquanto unidade de produção de bens educativos, parece-nos importante que a universidade consiga que os doentes possam usar formações universitárias curtas e longas, com diploma, como alavanca para um novo desenvolvimento pessoal e profissional. A passagem para o status de estudante representa uma transição social mobilizadora que permite à pessoa estruturar de modo diverso seu percurso biográfico, assim como identificar os recursos adquiridos durante a doença que ela deseja capitalizar em termos de competências a serem desenvolvidas, aprofundadas e aproveitadas em seu percurso pós-universitário.

A iniciativa da Universidade Pierre et Marie Curie (Paris 6 Medicina) foi seguida pela Universidade de Marseille e, mais recentemente, pela Universidade de Grenoble. Em 2014, a Conferência dos Presidentes de Universidades recebeu positivamente essa iniciativa e outros programas universitários voltados para os doentes estão sendo criados em outras universidades. Em 2015, a universidade dos pacientes domiciliada na Faculdade de Medicina alcançou outra etapa do seu desenvolvimento. Recebeu patrocínio vindo de uma Fundação (MSD Avenir) para lhe possibilitar desenvolver-se e implantar-se em outras universidades na França e no exterior. Um primeiro eixo de desenvolvimento remete à concepção de novos diplomas cujas ideias nos foram sugeridas pelos próprios doentes. Por exemplo, na volta às aulas de 2016 , um novo diploma trata de formação de pacientes acompanhantes do percurso "paciente em cancerologia". Com efeito, os doentes com câncer participando de nosso curso de educação terapêutica identificaram certo número de problemas ligados ao desenvolvimento das quimioterapias orais no tratamento do câncer, como a errância terapêutica dos doentes, seu sentimento de solidão em seu domicílio, a multiplicidade dos exames de verificação a serem realizados, a dificuldade para gerir as relações com os empregadores, a volta para a saúde, o vivido da remissão. Trata-se portanto de formar doentes com câncer para que desempenhem funções e missões nos hospitais ou nas redes junto a outros doentes no âmbito de uma estratégia de paciente-parceiro.

Outros doentes mostraram-se interessados pela criação de um curso universitário para se tornarem representantes dos usuários nas instâncias deci- sionais na área da saúde no âmbito da lei sobre a democracia sanitária. Um diploma universitário sobre a aprendizagem da democracia sanitária será inaugurado também a partir da volta às aulas de 2016. Um segundo eixo remete à criação de uma avaliação de competências para os doentes crônicos. A ideia é que todo doente crônico, a cada momento do seu percurso de tratamento, possa fazer uma avaliação das competências adquiridas no decorrer da doença e de seus tratamentos, assim como validar estas novas experiências no seu desenvolvimento profissional, ou até mudar de profissão e considerar novos caminhos de profissionalização, se assim o desejar. Esse balanço se faz necessário, pois no estado atual das coisas, um doente que se apresenta para uma avaliação profissional se vê, na maioria das vezes, excluído. Os períodos de doença formam um buraco, um vazio no seu currículo, e são tratados como ausências, uma parêntese fora do mundo, o que se constitui como uma experiência violentíssima para os doentes, os quais muitas vezes ouvem: "Ah, você estava doente, então isso não conta, claro, não se pode fazer nada com esse período." Trata-se portanto de desenvolver um programa de ação-pesquisa almejando a identificação das competências adquiridas pelos doentes por conta de sua doença e de construir ferramentas e um manual para os conselheiros de orientação profissional atuando nas áreas do trabalho e do emprego, suscetíveis de acompanhar o desenvolvimento profissional de pessoas doentes. Trata-se também de propor para os planos de saúde e de previdência cooperativos um novo serviço relativo a ajuda profissional, para complementar suas ofertas de ajuda material, psicológica e social. Com efeito, o doente é também um sujeito saudável do ponto de vista do emprego, no sentido em que suas capacidades antigas e novas devem poder, uma vez validadas, possibilitar um novo desenvolvimento das suas competências profissionais úteis para a coletividade e para seu projeto de desenvolvimento pessoal. Neste sentido, os doentes crônicos são verdadeiros operadores na organização das terapias, e é com a sua integração em todas as instâncias decisionais do sistema de saúde que poderemos melhorar o sistema de organização das terapias, pois eles apontam quais caminhos explorar, quais decisões tomar, quais orientações implementar. Não 
são meros beneficiários de tratamento, eles são coprodutores do tratamento (PEREIRA-PAULO; TOURETTE-TURGIS, 2016), eles sabem como melhorar o sistema de saúde e como otimizar o serviço médico dispensado para a coletividade.
É importante reconhecer a sua expertise de experiência e de uso, é importante abrir para eles as portas das universidades, pois os saberes dos quais são depositários pertencem ao patrimônio da humanidade.

\section{REFERÊNCIAS}

BÉZILLE, Hélène. L’autodidacte - entre pratiques et représentations sociales. Paris: L'Harmattan, 2003.

CHARON, Rita. Narrative medecine honoring the stories of illness. New York: New York University Press, 2006. DELORY-MOMBERGER, Christine. Biographie et éducation. Figures de l'individu-projet. Paris: Anthropos, 2003. DOMINICÉ, Pierre; JACQUEMET, Stéphane. Formation et santé. Savoirs, n. 19, p. 7-36, 2009.

FREIRE, Paulo. La pédagogie des opprimés. Paris: Maspéro, 1971.

HAMELINE, Daniel. Les objectifs pédagogiques en formation initiale et en formation continue. Paris: ESF, 1983.

JOUET, Emmanuelle, FLORA, Luigi, LAS VERGNAS, Olivier. Construction et reconnaissances des savoirs expérientiels des patients: Note de synthèse. Revue Pratiques de formation/Analyses, n. 58-59, p. 13-94, 2010.

LACROIX, A.; ASSAL, J-P. L'éducation thérapeutique du patient: nouvelles approches de la maladie chronique. Paris: Vigot, 1998.

LESOURD, Francis. L'homme en transition: éducation et tournants de vie. Paris: Anthropos, 2008.

NIEWIADOMSKI, Christophe. Valoriser d'autres approches cliniques que la seule clinique médicale. Savoirs, $\mathrm{n}$. 19, p. 44-47, 2009.

ORGANIZAÇÃO MUNDIAL DA SAÚDE (OMS). Rapport OMS Europe Therapeutic Patient Education. Copenhage, 1998.

PEREIRA-PAULO, L.; TOURETTE-TURGIS, C. Quand mon corps parle, qu'est-ce que j'apprends? In: DELORY-MOMBERGER (Dir.). Éprouver le corps - Corps appris, corps apprenant. Toulouse: Eres, 2016. p. 203-216.

TOURETTE-TURGIS, Catherine. Le Counseling: théorie et pratique. Paris: PUF, 1996. (coll. Que Sais-Je?)

TOURETTE-TURGIS, Catherine; THIEVENAZ, Joris. La reconnaissance du "travail" des malades: un enjeu pour le champ de l'éducation et de la formation. Les Sciences de l'éducation - Pour l'Ère nouvelle, v. 46, n. 4, p. 59-75, 2013.

VAN BALLEKOM, Karin. L'éducation du patient en hôpital. Pratiques \& politiques en Belgique, Royaume-Uni, France et Pays-Bas. Conclusions et recommandations pour la Belgique. Godinne, février 2008.

VYGOTSKI, Lev. Pensée et langage. Paris: Messidor, 1985.

Recebido em: 30.03 .2016

Aprovado em: 10.07.2016 